\title{
Ileocolonic Transposition Esophagogastric Bypass as an Antireflux Treatment for Corrosive Esophageal Injury
}

\author{
Yuda Handaya, Mukhamad Sunardi ${ }^{1}$ \\ Division of Digestive Surgery, Department of Surgery, Faculty of Medicine, Universitas Gadjah Mada/Dr. Sardjito Hospital, Yogyakarta; \\ ${ }^{1}$ Faculty of Medicine, Universitas Gadjah Mada/Dr. Sardjito Hospital, Yogyakarta, Indonesia
}

Because most surgeons perform an esophagectomy and colonic transposition as the main reconstruction method for patients with esophageal stenosis caused by swallowing corrosive materials, we report 2 cases in which ileocolonic transposition was used to treat such patients. Both patients displayed stenosis in the middle third of the esophagus. Their chief complaint was dysphagia. Ileocolonic transposition using vascularization of the Drummond and ileal arteries was followed by a prepared ileocolic graft by ligating ileocolic vessels. We performed an ileocolonic transposition esophagogastric bypass without an esophagectomy. All surgeries resulted in minimal intraoperative bleeding. Patients experienced no leakage, postoperative fistulas, dysphagia, or postoperative reflux. Three weeks after surgery, 1 patient experienced reversible hoarseness caused by extensive laryngeal-nerve manipulation. Cumulatively, ileocolonic transposition with cervical anastomosis for the treatment of patients with esophageal stenosis caused by corrosive esophageal injury can be considered to be an antireflux treatment because the ileocaecal sphincter is maintained.

Keywords: Esophageal stenosis; Ileocolonic transposition; Esophagogastric bypass; Anti-reflux

\section{INTRODUCTION}

Ingestion of corrosive materials is common in Asia, and it is a frequent cause of morbidity secondary to an intense fibrotic reaction and stricture formation in the esophagus. Patients who ingest caustic liquid materials experience esophagitis, which can result in esophageal stenosis in the future [1]. The type and quantity of the ingested corrosive material, the duration of the mucosal injury, and the effectiveness of first aid are key factors contributing to esophageal stricture development. Esophageal corrosive injury does not require surgical intervention in the early stage, nor do first- and second-degree burns. However, conservative treatment is not generally successful for healing esophageal strictures initi-

Received: June 9, 2017 - Accepted: June 30, 2017

Correspondence to: Yuda Handaya, M.D.

Division of Digestive Surgery, Department of Surgery, Faculty of Medicine, Universitas Gadjah Mada/Dr. Sardjito Hospital, Jl. Kesehatan No. 1

Yogyakarta 55281, Indonesia

Tel: +62-274581333, Fax: +62-274581333

E-mail: yudahandaya@ugm.ac.id

(C) 2017 The Korean Society of Coloproctology

This is an open-access article distributed under the terms of the Creative Commons Attribution NonCommercial License (http://creativecommons.org/licenses/by-nc/4.0) which permits unrestricted noncommercial use, distribution, and reproduction in any medium, provided the original work is properly cited. ated by a third-degree burn. Medical literature on the ingestion of corrosive materials concentrates primarily on incidents occurring in children because the ingestion of corrosive materials is generally accidental for adult patients, except for those attempting suicide.

For adult cases, the available data are extremely limited. Studies include small patient groups only and have typically focused on medical treatments. The literature describing available surgical treatments emphasizes ileocolonic transposition as the main reconstruction method, and esophagectomies are rare. Recent data reveal that surgeons rarely prefer a colon transposition, an esophagectomy, or an esophagogastroplasty for reconstruction [2]. Here, we report two cases of caustic esophageal stricture, which were treated by ileocolonic transposition esophagogastric bypass using ileocaecal segment to prevent reflux and cervical fistula.

\section{CASE REPORTS}

\section{Case 1}

A-35-year-old man experiencing dysphagia and nasogastric tube (NGT) installment failure caused by esophageal stricture was studied. The patient complained of dysphagia for 3 months before coming to the hospital. The patient was also diagnosed with type 
Volume 33, Number 4, 2017

2 diabetes mellitus. He was discharged from the hospital with controlled diabetes, and the dysphagia was treated conservatively. The patient had a history of swallowing corrosive materials that had high concentrations of alkali liquid (Porstex). The patient's general appearance was poor, but no abnormalities were found during the general examination or laboratory tests. Esophagography showed severe partial obstruction of the esophagus (Fig. 1A, B). Gastroscopy revealed a cicatrix on the mucosal layer of the esophageal wall, in addition to a narrowing of the esophagus lumen caused by the stricture (Fig. 1C, D). A biopsy of the esophageal tissue showed that the esophageal epithelium lacked the submucosal layer, but no cancer or other obvious abnormalities were observed.

Ileocolonic transposition was performed on this patient. The patient had dysphonia after surgery, and the NGT was removed 7 days after surgery. The patient continued on a liquid diet and was discharged from the hospital on postoperative day nine. The patient was advised to come to the hospital every week. The patient's dysphonia was reported to have improved, resulting in a normal voice after two weeks. The patient was advised to eat a regular meal, and at four weeks following surgery, no complaints of dysphonia and no reflux after surgery were reported.

\section{Case 2}

A 20-year-old man's chief complaints were difficulty swallowing food, regurgitation, vomiting, and hypersalivation. These symptoms had lasted for approximately 6 weeks. The patient could only consume a small amount of milk or porridge. The patient had attempted to commit suicide 3 years earlier by drinking Porstex, a corrosive basic liquid. He had been admitted to a type C rural hospital for 1 month and was then discharged after he could swallow mushy rice or porridge. One year before he came to the Digestive Surgery Clinic, he attempted to commit suicide again by drinking Porstex and was admitted to a type $\mathrm{C}$ rural hospital for 2 months. One month before he came to the hospital, the patient underwent a barium meal and endoscopic examination. The result of that barium meal examination revealed the presence of a one-third distal esophageal stricture approximately $3 \mathrm{~cm}$ in length at the 8th thoracic vertebra (Fig. 2).

Upon physical examination, the patient displayed poor nutrition, but otherwise the patient's test results were normal. The ileocolonic transposition procedure was performed on this patient.

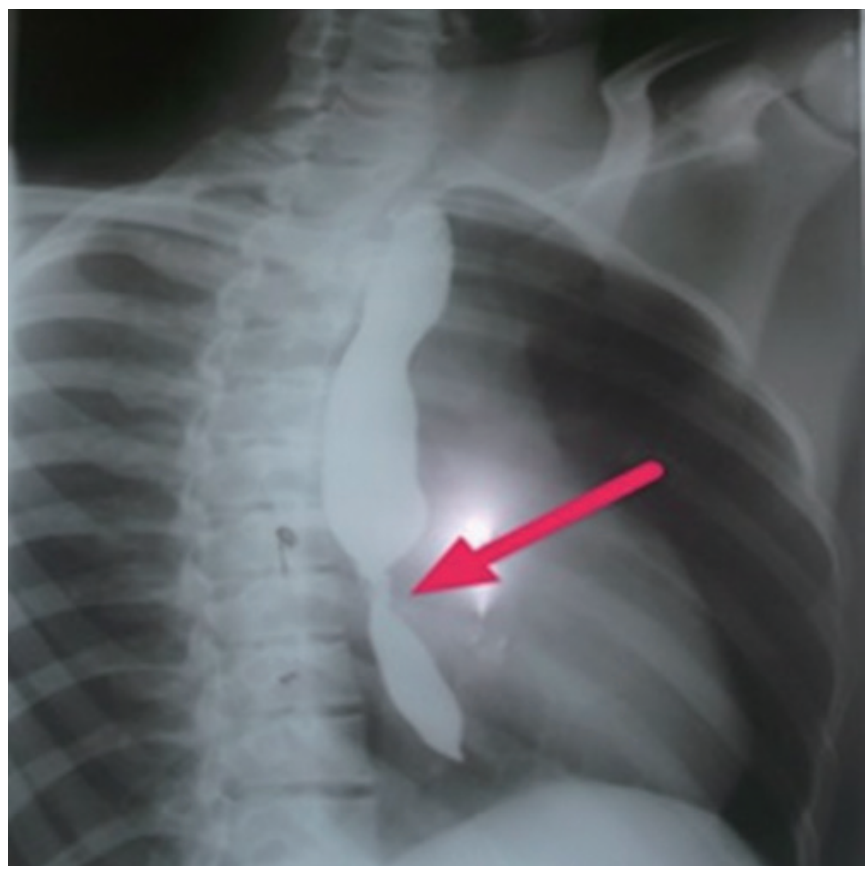

Fig. 2. A barium X-ray showed a middle-third esophageal stricture. The constriction of the stricture esophagus has been showed by arrow sign.
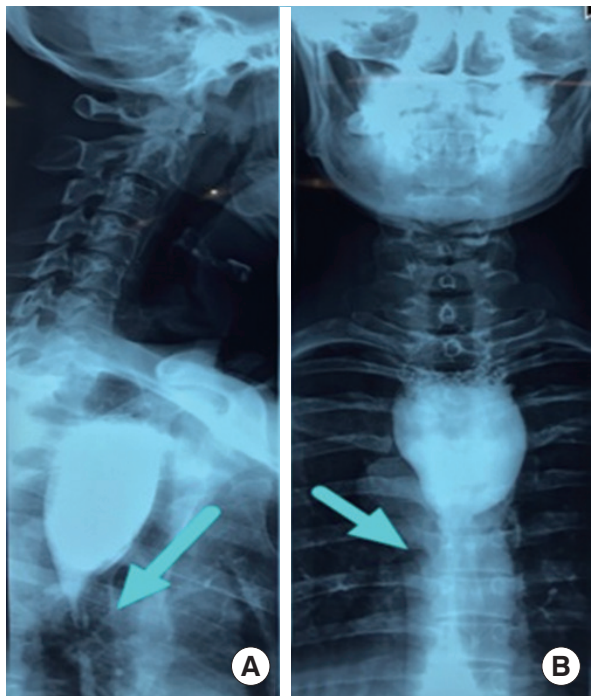
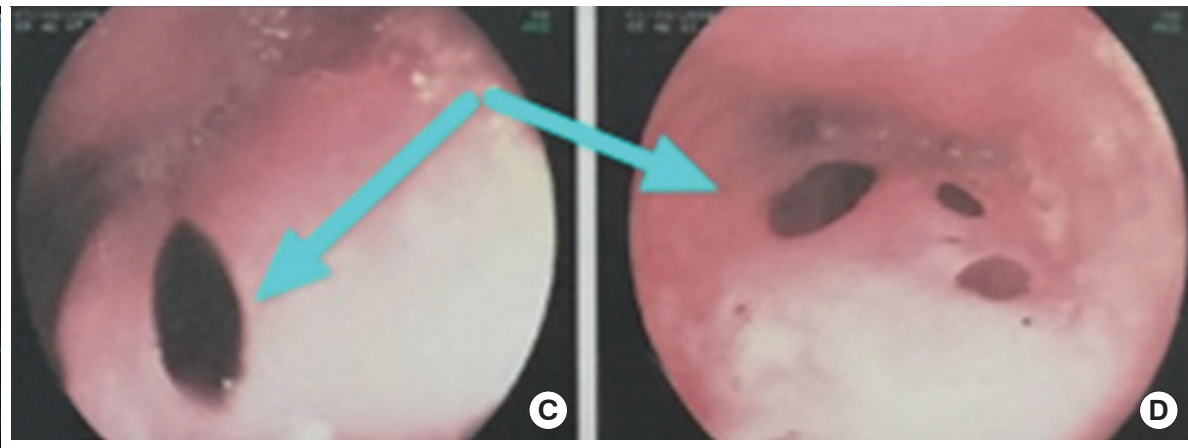

Fig. 1. Esophagography revealed severe partial obstructions of the middle third of the esophagus: lateral (A) and anterior view (B). Esophagogastroduodenoscopy showed a narrowing (arrow) (C), and cicatrix of the esophageal lumen (arrow) (D). 


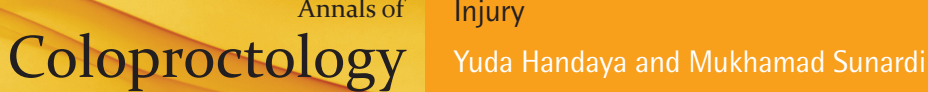
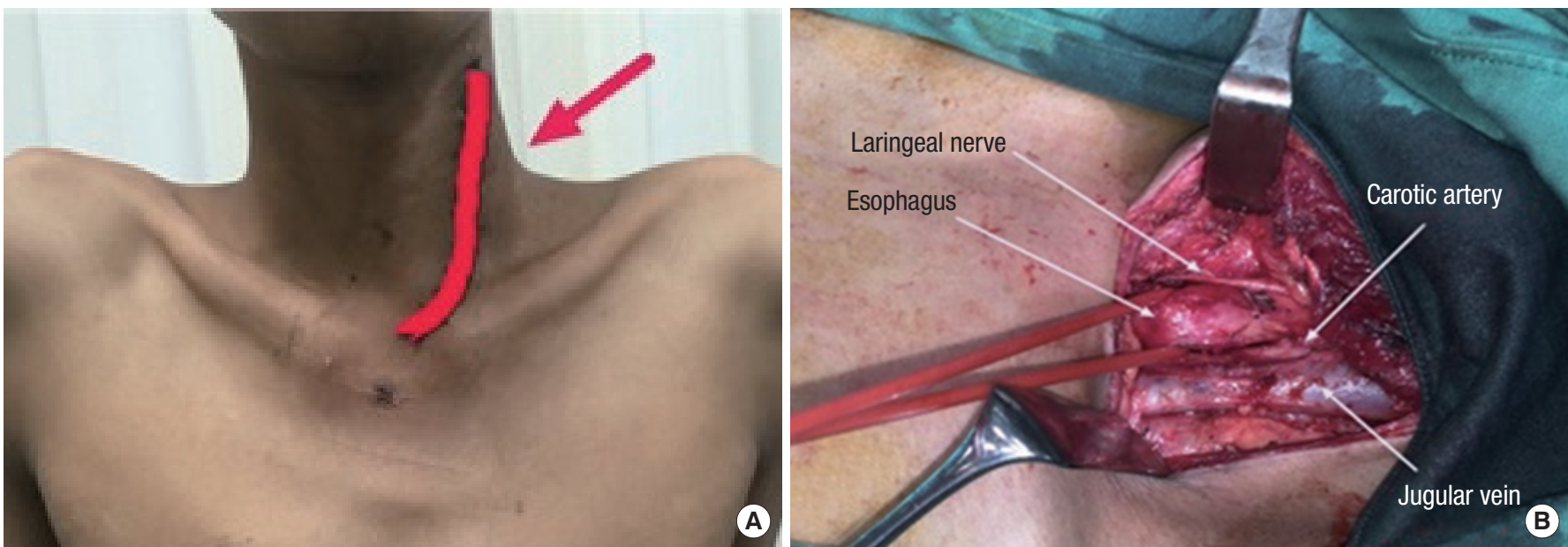

Fig. 3. Cervical "J" shaped incision (A; arrow) and preparation and isolation of the cervical esophagus (B).

Observation on postoperative day 1 was carried out in the intensive care unit. Vital signs were monitored, as were daily products from the drain. The patient was fasted for 2 days and given nutrition through a NGT afterward. During the next 10 days, no oral nutrition was given. The NGT was removed after 10 days, and on day 11 , the patient was given a liquid diet orally. No anastomotic leakages or postoperative infections were encountered. On day 15 , the patient could swallow soft porridge and was discharged. One month later, the patient returned to the Digestive Surgery Clinic and was already on a mushy rice diet with no complaints. A barium-ingestion X-ray examination was performed, and counseling was given by the Psychiatry Department.

\section{ILEOCOLONIC TRANSPOSITION PROCEDURE}

We performed an esophagus and colon preparation the day before surgery with $500 \mathrm{~mL}$ of warm normal saline. Surgery was performed with a "J" cervical incision following the edge of the anterior part of the sternocleidomastoid muscle (Fig. 3A). We dissected the platysma muscle, performed a blunt dissection between the cervical muscle and the sternocleidomastoid muscle, and then retracted laterally from the sternocleidomastoid muscle. We performed a sharp dissection of the omohyoid muscle and medial retraction of the strap muscles in order to visualize the lateral edge of the thyroid, the jugular vein, and the carotid artery. This was followed by a fingertip blunt dissection of the cervical and thoracic part of the esophagus. The esophagus was identified, prepared, and isolated using a nelaton (Fig. 3B).

The abdominal phase was performed via a midline incision. The ileocecocolic graft was prepared by freeing the caecum, ascending colon, transverse colon, and terminal ileum from the white line. This was followed by preparation of the vascular graft by ligation of the right branch of the middle colic artery, right colic artery, and ileocolic artery, in addition to maintenance of the marginal artery of Drummond and the source of vascularization coming from the middle branch of the middle colic artery (Fig. 4).

Retrosternal tunneling was performed via blunt dissection retrosternally without opening the thoracic cavity. Esophageal resection was performed with 2 index fingers because the axis of the sternum was long enough (approximately 3 fingers). We also used a curve clamp and gauze. Surgical gauze was placed on the substernal track from the jugular notch to the xiphoid process. An incision was made on the left lateral region of the neck, and it was deepened layer by layer to the sternocleidomastoid muscle. The jugular vein was identified and separated from the surrounding tissue. The carotid artery was identified and separated from the surrounding tissue. The trachea and esophagus were identified. Surgical gauze was placed around the esophagus and in the substernal track from the jugular notch to the xiphoid process. The procedure was continued with a laparotomy. A midline incision from the xiphoid process to 3 fingers above the pubic symphysis was made. The terminal ileum, caecum, ascending colon, and transverse colon were separated from the surrounding tissue. The right colic artery was ligated as distal as possible, and an appendectomy was done. The ileum was resected $10 \mathrm{~cm}$ from the ileocecal junction, and the transverse colon was resected with the middle colic artery. The length of the graft was calculated (Fig. 5A). A pull string suture with silk 2.0 was performed on the terminal ileum using a $24 \mathrm{~F}$ catheter with a $5-\mathrm{mL}$ balloon. The terminal ileum was pulled proximally and drained using saline until clean.

An ileoesophageal anastomosis was done, and the NGT was inserted into the transverse colon and simple-interrupted sutured (Fig. 5B). An end-to-side gastro-transverse-ostomy anastomosis was performed and continued with an ileotransverseostomy anastomosis. The abdominal cavity was irrigated using $0.9 \% \mathrm{NaCl}$, a drainage tube was placed suprasternally, surgical wounds on the 


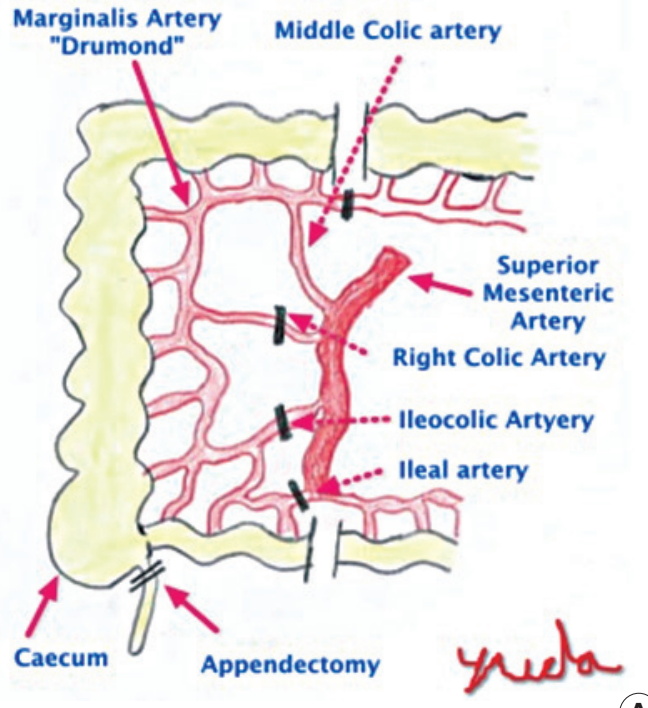

(A)

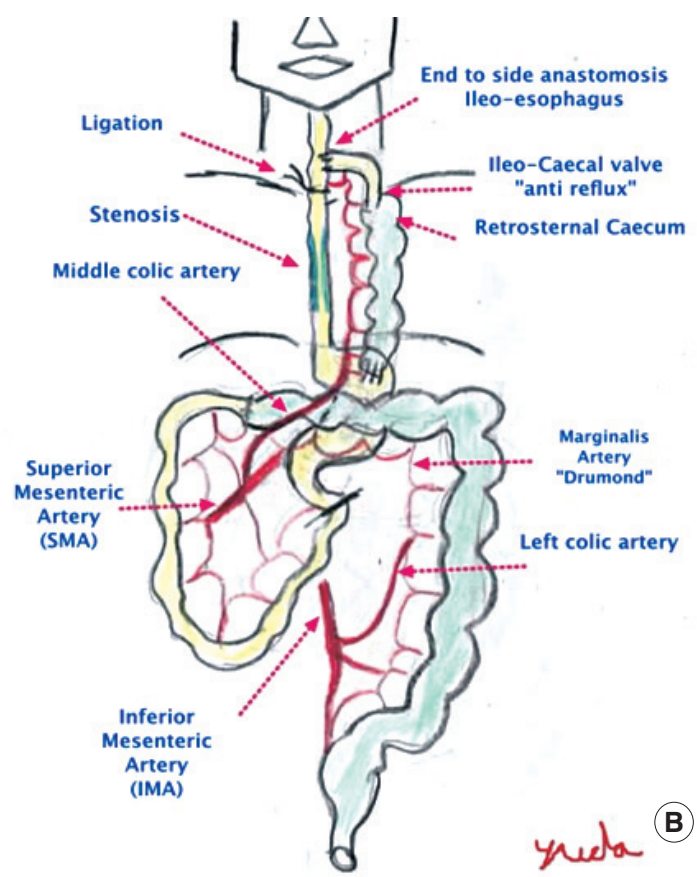

Fig. 4. Diagrams of the preparation of the ileocolonic graft vascularization with maintenance of the marginal artery of Drummond and the middle colic artery (A) and the ileocolonic transposition without esophageal resection (B).
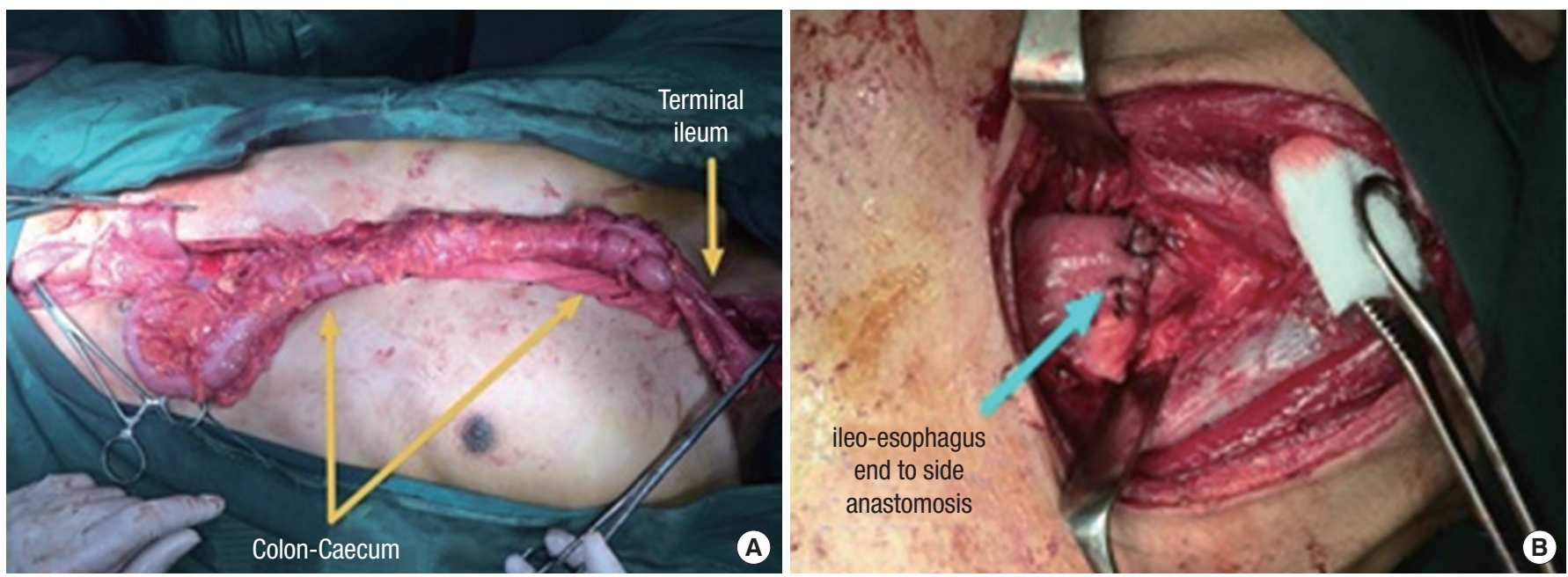

Fig. 5. Calculating the length of the graft (A) and the ileoesophageal anastomosis (B).

neck were sutured layer by layer, two drainage tubes were placed in the abdominal cavity, and the surgical wounds on the abdomen were sutured layer by layer.

\section{DISCUSSION}

The ingestion of corrosive materials is common in Asia, and it is a frequent cause of death in India. The incidence of gastric outlet obstruction has been reported to range from $10 \%$ to $37.5 \%$ of patients [1]. Our cases show that the ingestion of corrosive materials in adults causes benign esophageal stricture in the long segment of the middle part of the esophagus. Common causes of benign esophageal stricture include peptic injury, anastomotic strictures, radiation injury, caustic ingestion, Schatzki rings, and esophageal webs [3]. Esophageal burns due to accidental ingestion of corrosive substances are the most common cause of esophageal stric- 
ture development. A complication of a caustic esophageal burn is the development of a dense collagen scar at the injury site [4]. Severe injuries to the upper gastrointestinal tract from the ingestion of corrosive materials include erosions, esophagitis, gastritis, and even necrosis and sloughing. Corrosive burns lead to an intense fibrotic reaction and stricture formation in the esophagus and/or stomach [1].

In general, the ingestion of alkalis results primarily in pharyngeal and esophageal burns. This is consistent with what we observed in our patient cases. The esophageal stricture site is where acids tend to spare these structures and destroy the stomach. Either substance, alkali or acid, in a large enough amount can cause severe damage to both the esophagus and the stomach in approximately $20 \%$ of cases [1]. Ingestion of caustic materials, such as the swallowing of a detergent, can produce progressive and devastating injuries in the esophagus and the stomach.

One of the most important outcomes of corrosive esophagitis is stricture formation, and this injury is often quite resistant to treatment. Because of its important influence on the patient's quality of life, esophageal stenosis poses a serious problem and requires therapeutic solutions. The traditional treatment for an esophageal stricture is intraluminal dilation. However, this occasionally may not provide adequate esophageal lumen capacity or yield significant symptom-free intervals. In fact, restructuring after dilation is common and challenging. The key steps in the initiation of scar formation are fibroblast proliferation and collagen formation secondary to mucosal injury.

A well-documented treatment option for esophageal atresia is the replacement of the defective esophagus with the interposition of the ascending or transverse colon [5]. Colonic transposition changes the gastrointestinal anatomy more than gastric pull-up does because it comes with increased morbidity and mortality. Therefore, colonic transposition should be performed only on certain patients whose stomachs are not suitable for reconstruction. Yararbai et al. [6] reported 2 cases of graft necrosis in $34 \mathrm{pa}-$ tients who had undergone colonic transposition. In another study, which included 82 patients who had undergone colonic transposition, 6 deaths were reported. Two of these patients died from graft necrosis, 2 from aspiration pneumonia, 1 from bacterial peritonitis due to abdominal anastomotic leakage, and 1 from disseminated intravascular coagulopathy [7]. Knezevi et al. [8] reported a study that included 336 patients who had undergone colonic transposition and had experienced early postoperative complications. These complications included anastomotic leakage, colonic necrosis, and hemopneumothorax. They reported an early postoperative complication rate of $26.49 \%$. Furthermore, the authors found that cervical anastomotic stricture, peptic colonic ulceration, bowel obstruction, and thoracic outlet compression were late postoperative complications occurring at a rate of $14 \%$ [2].

We performed ileocolonic transposition for a long-segment esophageal stricture. Our surgery used the middle colic artery as the main blood supply. In most clinical centers, colonic transposi- tion has been considered the best surgical treatment for these cases. We did not perform a thoracotomy because caustic injury to the esophagus is not a malignant process, as has been reported by Harlak et al. [2].

Several complications associated with this surgical approach were observed. The most serious was intrathoracic necrosis of the transposed colon in the early postoperative period, which occurred in $12.5 \%$ of patients. This was usually because of technical errors and/or failure to recognize inadequate blood supply to the interposed colon. The reported incidence of this complication ranges from $3 \%$ to $15 \%$ in pediatric surgery, and it is frequently lethal. Other reported complications are late necrosis of the transposed colon, gastric reflux to the interposed colon, cervical anastomotic leakage, and kinked esophagocolic anastomosis in the neck. Our study has led us to modify some surgical steps and technical details of this "conventional" procedure in an effort to minimize the rate of complications. The purpose of this report is to present our experience with esophagocoloplasty in adults, which we performed with some technical modifications. Special emphasis has been given to the double blood supply of the interposed colon, which was explained by Tannuri et al. [9]. An anastomotic stricture of the esophagoesophagostomy in infants after tracheoesophageal fistula repair is common. Fortunately, most strictures respond to bougie or pneumatic balloon dilation [10]. We performed surgery with a long graft ileum $10 \mathrm{~cm}$ in length. We maintained the ileo artery and placed the caecum retrosternally to prevent necrotic complications resulting from vascularization disturbance following sternal or clavicle pressure.

The nipple valve at the ileocolic junction acts as an antireflux mechanism, which was described by Touloukian and Tellides [11]. Lima et al. [12] reported good outcomes in their study of 11 children who had undergone ileocolic esophageal replacement. This is the reason we used the ileocolonic segment for esophageal replacement in these cases. We ligated with silk 1.0 at the distal esophagus. An ileoesophageal anastomosis without an esophagectomy is relatively easier and quicker to perform and does not require a thoracotomy [13] to prevent further blood loss. This also reduces surgery times.

Ileocolonic transposition is preferable for managing long and multiple esophageal strictures. Temporary dysphonia was a postoperative complication experienced by 1 patient. Thus, ileocolonic transposition with cervical anastomosis is a safe procedure, and it can be considered to be an antireflux treatment because it maintains the ileocaecal sphincter. It can also be performed for the treatment of patients with esophageal stenosis caused by corrosive esophageal injury.

\section{CONFLICT OF INTEREST}

No potential conflict of interest relevant to this article was reported. 


\section{ACKNOWLEDGMENTS}

We thank the surgical team, especially to Marijata, Meinard, and Uras, and the nursing staff who were involved in the patients' care and surgery.

\section{REFERENCES}

1. Ansari MM, Haleem S, Harris SH, Khan R, Zia I, Beg MH. Isolated corrosive pyloric stenosis without oesophageal involvement: an experience of 21 years. Arab J Gastroenterol 2011;12:94-8.

2. Harlak A, Yigit T, Coskun K, Ozer T, Mentes O, Gülec B, et al. Surgical treatment of caustic esophageal strictures in adults. Int J Surg 2013;11:164-8.

3. Nguyen NQ, Shah JN. Tranvering difficult esophageal strictures from the oral approach. Tech Gastrointest Endosc 2008;10:142-8.

4. Ocakci A, Coskun O, Tumkaya L, Kanter M, Gurel A, Hosnuter M, et al. Beneficial effects of Ebselen on corrosive esophageal burns of rats. Int J Pediatr Otorhinolaryngol 2006;70:45-52.

5. Law R. A surprise case of colonic interposition. Radiography 2006; 12:31-3.

6. Yararbai O, Osmanodlu H, Kaplan H, Tokat Y, Coker A, Korkut M, et al. Esophagocoloplasty in the management of postcorrosive strictures of the esophagus. Hepatogastroenterology 1998;45:5964.
7. Deng B, Wang RW, Jiang YG, Gong TQ, Zhou JH, Lin YD, et al. Prevention and management of complications after colon interposition for corrosive esophageal burns. Dis Esophagus 2008; 21:57-62.

8. Knezevic JD, Radovanovix NS, Simic AP, Kotarac MM, Skrobic $\mathrm{OM}$, Konstantinovic VD, et al. Colon interposition in the treatment of esophageal caustic strictures: 40 years of experience. Dis Esophagus 2007;20:530-4.

9. Tannuri U, Maksoud Filho JG, Maksoud JG. Esophagocoloplasty in children: surgical technique, with emphasis on the double blood supply to the interposed colon, and results. J Pediatr Surg 1994;29:1434-8.

10. Heran MK, Pham TH, Butterworth S, Robinson A. Use of a microporous polytetrafluoroethylene catheter balloon to treat refractory esophageal stricture: a novel technique for delivery of mito-mycin C. J Pediatr Surg 2011;46:776-9.

11. Touloukian RJ, Tellides G. Retrosternal ileocolic esophageal replacement in children revisited. Anti-reflux role of the ileocecal valve. J Thorac Cardiovasc Surg 1994;107:1067-72.

12. Lima M, Destro F, Cantone N, Maffi M, Ruggeri G, Dòmini R. Long-term follow-up after esophageal replacement in children: 45-Year single-center experience. J Pediatr Surg 2015;50:1457-61.

13. Gvalani AK, Deolekar S, Gandhi J, Dalvi A. Antesternal colonic interposition for corrosive esophageal stricture. Indian J Surg 2014; 76:56-60. 